\title{
Permanent Neonatal DM in Monozygotic Twins with p.C109Y Mutation in INS Gene: First Report from Saudi Arabia \\ Iman M. Talaat ${ }^{1,2}$, Naglaa Mohamed Kamal ${ }^{3,4 *}$ and Hamid Alghamdi ${ }^{2}$
}

${ }^{1}$ Faculty of Medicine, Ain Shams University, Egypt

${ }^{2}$ Consultant Pediatrician, Prince Mansour Hospital, Taif, Saudi Arabia

${ }^{3}$ Faculty of Medicine, Cairo University, Cairo, Egypt

${ }^{4}$ Consultant Pediatrician, Al-Hada Armed Forces Hospital, Taif, Saudi Arabia

\begin{abstract}
Insulin gene mutation (INS) is the second most common cause of permanent neonatal diabetes (PNDM). We present the $1^{\text {st }}$ cases of Saudi monozygotic twins with permanent neonatal diabetes mellitus who had simultaneous onset of disease due to p.C109Y (p.Cys109Tyr, c.326G>A) heterozygous missense mutation in exon 3 of the insulin (INS) gene. The twin patients had the same mutation while their parents are unaffected with normal genetic testing suggesting that this mutation had raised de novo. This p.C109Y mutation affects a highly conserved cysteine residue which is crucial for protein folding. Subjects with this form of diabetes will need lifelong insulin therapy.
\end{abstract}

Keywords: Permanent neonatal Diabetes; Monozygotic; Twins; INS gene; Saudi Arabia

\section{Introduction}

Neonatal diabetes mellitus (NDM) was previously defined as diabetes with onset within 6 weeks from birth that requires insulin therapy for at least 2 weeks. The new definition recently adopted, includes patients with diabetes onset within 6 months of age [1]. NDM was considered exceedingly rare condition but actually its incidence varies from country to another [1]. High incidence of 1 in 21,196 live births was reported from Saudi Arabia [2].

NDM can be classified according to the duration of insulin dependence in the first months/years of life and according to the molecular mechanisms responsible for the severe insulin secretion deficiency into 2 types; transient or permanent [3]. The number of cases of neonatal diabetes continues to accumulate, but the available, combined data indicate that somewhat over half $(\sim 57 \%)$ of NDM cases are transient [4].

Permanent neonatal diabetes mellitus (PNDM) /monogenic diabetes of infancy (MDI) is a rare condition associated with defects in genes that play major roles in pancreatic beta cell development and function; mutations in the genes encoding the ATP-sensitive potassium channel (K-ATP) subunits, KCNJ11 (encoding KIR 6.2 subunit), $A B C C 8$ (encoding SUR1 subunit) and insulin (INS), account for most cases of PNDM/MDI [4-10]. Moreover, individuals with some exceedingly rare forms of syndromic PNDM may bear recessive mutations in several genes, including PDX1, EIF2AK3, PTFIA, GLIS3, RFX6 or FOXP3 [11-17], while recessive mutations in glucokinase give rise to isolated neonatal diabetes [18].

In fact undoubtedly the discovery of INS mutations on chromosome 11 p15 [8] was the most important discovery in PNDM from the clinical perspective in the last few years [8]. It accounts for about 10-15\% of NDM cases $[3,9,19,20]$. Both heterozygous and homozygous INS mutations can cause NDM. The heterozygous coding mutations in the INS gene are considered the second most common cause of isolated PNDM after the activating mutations in the $\mathrm{K}_{\mathrm{ATP}}$ channel genes $[3,8,9,20]$. Recently Raile et al. reported INS deletions in homozygous and heterozygous individuals [21].

\section{Case Report}

We here in report the first cases of PNDM due to INS heterozygous mutation from Saudi Arabia in 15 years-old identical twin females, born to non-consanguineous parents. They were delivered at term by normal spontaneous vertex vaginal delivery with uneventful antenatal and postnatal periods. Family history was negative for DM. At birth, their general condition was unremarkable with birth weight $2.3 \mathrm{~kg}$ (twin 1) and $2.1 \mathrm{~kg}$ (twin 2). At the age of 3 months, their mother noticed irritability and fussiness with failure to gain weight for both of her daughters simultaneously. Random blood glucose was checked and found to be $340 \mathrm{mg} / \mathrm{dl}$ (twin 1) and $500 \mathrm{mg} / \mathrm{dl}$ (twin 2) with no ketosis. Thyroid function tests and lipid profile were normal. Structural diseases of the pancreas were excluded by ultrasonography of the abdomen. They were started on NPH insulin with dose of about 1 unit/kg/day. Glutamic acid decarboxylase-65 antibody (GAD-65) and anti-islet cell antibodies were negative. Celiac profile was also negative. Basal and glucagon stimulated C-peptide levels were undetectable (reference range: 1.1-4.4 ng/mL). Since diagnosis, the patients are being followed up and they are now 15 years old with average weight and height and normal motor, mental and pubertal development with no extrapancreatic disease. They are currently on insulin glargine only with a dose of about 1 unit per $\mathrm{kg}$ and refusing the short acting analogues with poor glycemic control (HbA1C between 10-14\%). As previously reported by Kamal Alanani and Alsulaimani, low awareness and persistent denial of the parents about the fact that their children are diabetic is the greatest obstacle Pediatricians meet in Saudi Arabia [22]. We faced that in our patients whose parents are very poorly compliant to give proper insulin regimens to their daughters. Their parents were

*Corresponding author: Naglaa Mohamed Kamal, Pediatrics, Associate Professor of Pediatrics, Faculty of Medicine, Cairo University, Cairo, Egypt, Tel: 00201141991114; E-mail: nagla.kamal@kasralainy.edu.eg

Received December 27, 2013; Accepted January 29, 2014; Published February 05, 2014

Citation: Talaat IM, Kamal NM, Alghamdi H (2014) Permanent Neonatal DM in Monozygotic Twins with p.C109Y Mutation in INS Gene: First Report from Saudi Arabia. J Diabetes Metab 5: 332. doi:10.4172/2155-6156.1000332

Copyright: @ 2014 Talaat IM, et al. This is an open-access article distributed under the terms of the Creative Commons Attribution License, which permits unrestricted use, distribution, and reproduction in any medium, provided the original author and source are credited. 
Citation: Talaat IM, Kamal NM, Alghamdi H (2014) Permanent Neonatal DM in Monozygotic Twins with p.C109Y Mutation in INS Gene: First Report from Saudi Arabia. J Diabetes Metab 5: 332. doi:10.4172/2155-6156.1000332

Page 2 of 4

interviewed many times by multi-disciplinary team approach including; the pediatric endocrinologist, dietitians, nutritionists, health educators, diabetic educators, social workers, and psychiatrists, but with poor outcome. The child neglect committee was also involved. Currently, our main concern is to convince the parents for insulin pump therapy with the fact that it will be provided free of charge to their twins!

Genetic testing was carried for the patients and their parents. Sequence analysis of coding and flanking intronic of the KCNJ11 gene (NM_000525.3), ABCC8 gene (U63421 and L78208), EI2AK3 gene (AF110146.1) and INS gene (NM_000207.2) were done. Genetic tests for mutations in the gene subunits of the ATP-sensitive potassium channel, which are commonly associated with NDM, were negative. Both the twin sisters had a heterozygous missense mutation, (p.Cys109Tyr, c.326G $>A$ ) in exon 3 of the INS gene (Figure 1). This mutation results in the substitution of tyrosine for cysteine at codon 109. The mutation was not detected in the parental samples and it is therefore likely that the mutation has raised de novo (Figure 1) (Parents tested by Sanger sequencing). The twins tested using a set of microsatellite markers (powerplex 16) and results are consistent with them being monozygous. Figure 2, illustrates the monozygosity of the twin patients.

\section{Discussion}

Neonatal diabetes mellitus due to insulin gene mutation constitutes around $10-15 \%$ of all PNDM in some reports $[3,9,19,20]$, while in others it reached up to $20 \%$ as in the ISPAD cohort compared with $4 \%$ for $A B C C 8$ and $35 \%$ for KCNJ11 mutations [3]. Compared to $K_{-A T P}$ channel mutations, cases with INS mutations have a later presentation of diabetes (our twins presented at the age of 3 months) [3]. Several studies using linkage and candidate gene-based approaches have reported heterozygous missense mutations in the insulin gene

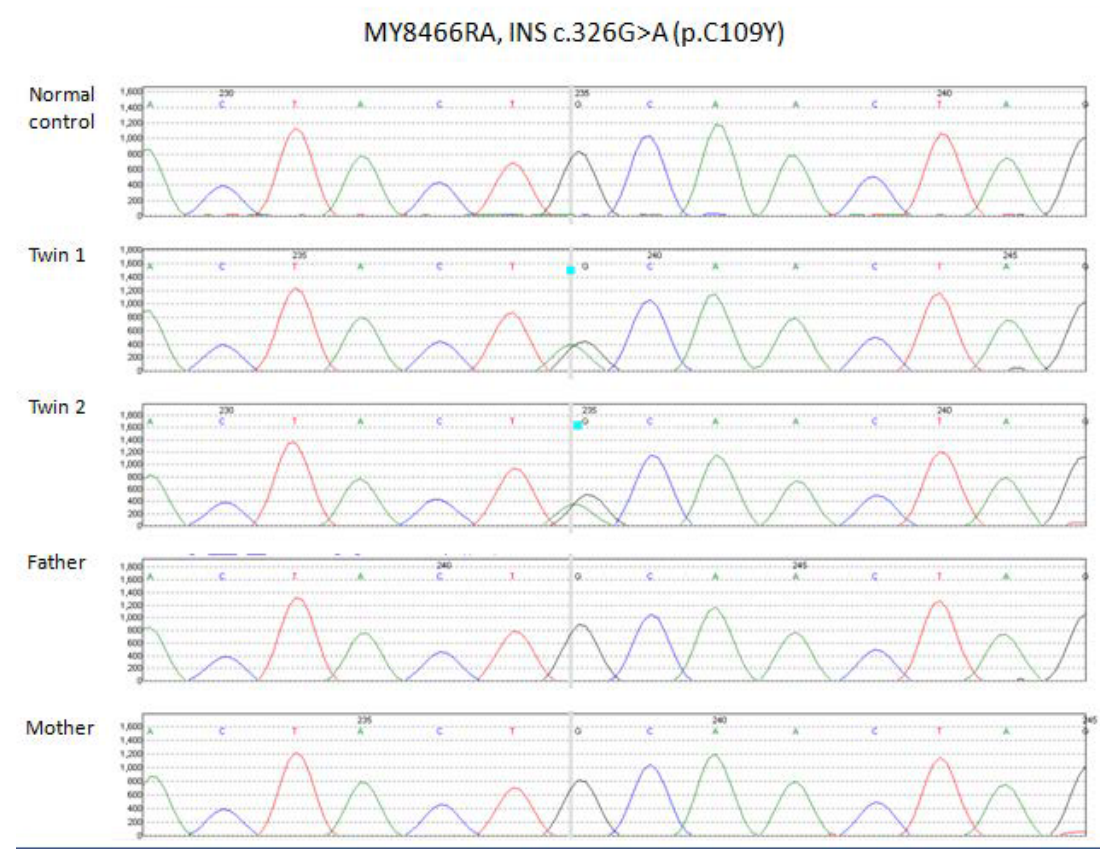

Figure 1: Mutation Chromatography showing the mutation in both twins and the wild type in the parents.

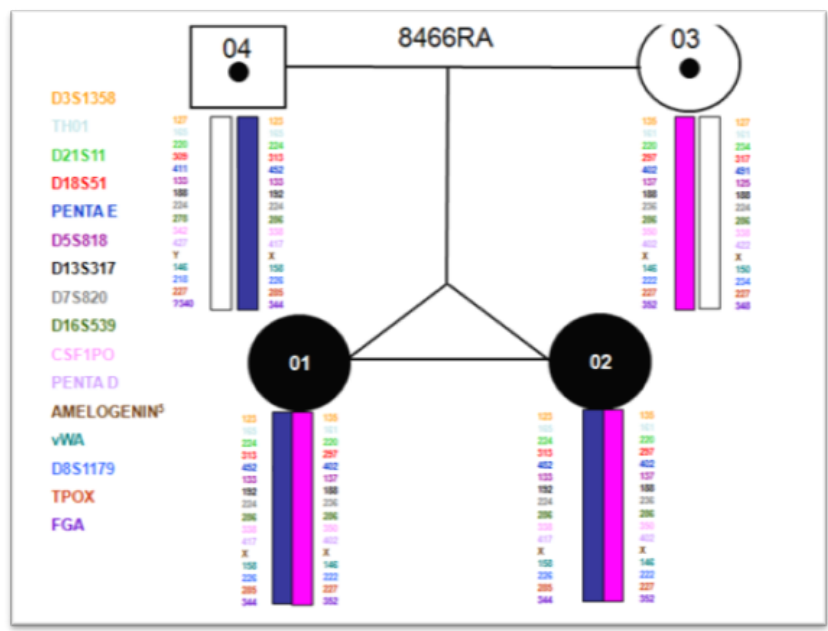

Figure 2: Diagram showing the monozygozisity of the twin patients 
causing permanent neonatal diabetes mellitus [3,8,9,20,23]. In 2007 Stoy et al. reported 10 heterozygous mutations in the INS gene in 16 probands with PNDM namely; A24D, G32S, G32R, C43G, G47V, F48C, G90C, C96Y, Y108C and R89C [8]. Polak et al. 2008 reported also the A24D, R89C, and C96Y mutations [3]. In 2012, Catli et al. reported a novel p.L30Q mutation [24]. We hereby report second siblings and $1^{\text {st }}$ twins with a new mutation p.C109Y in the INS gene after the one recently reported by Bee et al. [25].

This cysteine residue at codon 109 is highly conserved across species and the mutation abolishes a cysteine residue that is crucial for insulin folding [8] results in the formation of abnormally folded proinsulin molecules which are consequently degraded in the endoplasmic reticulum. This leads to severe endoplasmic reticulum stress followed by $\beta$ cell death from apoptosis. Disulfide bonding seems to be crucial for proinsulin folding in the endoplasmic reticulum, and about $60 \%$ of the insulin gene mutations disrupt disulfide bridge formation within this protein either by substitution of a cysteine residue or by the creation of an additional cysteine [20].

Germ line mosaicism was reported involving either KCNJ11 mutation [26] or insulin gene [23,25]. Although we shared Bee et al. $[25,26]$ same mutation but in their report the father had somatic mosaicism leading to transmission of PNDM to his children. Low level mutation was detected in the father's sequencing trace. Real-time polymerase chain reaction analysis showed that he had approximately $73 \%$ of the mutant allele relative to his affected son. This was in contrary to our report where the parents' genetic testing was completely normal. Age of onset in our reported patients (3 months) was comparable to that in the siblings reported by Bee et al. [25] (3 and 7 months).

Clinically, patients with an insulin gene mutation have severe hyperglycemia, and ketoacidosis [3,20,27], however, presentation is variable and, of these patients, only $40 \%$ had marked hyperglycemia and about $59 \%$ had ketoacidosis [20]. The presented patients had marked hyperglycemia and no previous history of diabetic ketoacidosis. Birth weight is variable may be low or high depending on the rate of reduction of $\beta$ cell in utero or in the first year of life [8]. The birth weight of our twins was normal, which is consistent with the birth weight of most patients with insulin gene mutation in the study of Colombo et al. [9].

Since INS is mostly expressed in pancreatic $\beta$-cells, the affected patients do not show any extrapancreatic features which are consistent with our findings. In addition to causing NDM, INS mutations may present acutely after the first 6 months of age and even beyond the age of one year, when monogenic diabetes becomes exceedingly rare [28]. Furthermore, up to $70 \%$ of the mutations are de novo, so that family history of early-onset diabetes is lacking which is in accordance with our patients. It is therefore likely that some patients with an INS mutation are clinically indistinguishable from early-onset type-1-DM. In these cases, routine measurement of pancreatic autoantibodies in young children with diabetes may be a helpful tool to identify candidates for genetic testing [29]. In our patients, both GAD-65 and ICA antibodies were negative.

Based on the study carried by Habeb et al. [2] regarding the etiology of neonatal diabetes in KSA, where neither KCN11 nor ABCC8 nor INS mutation were detected, our twins are considered the first reported cases of PNDM with insulin gene mutation from Saudi Arabia.

A better understanding of the mechanism(s) leading to $\beta$-cell dysfunction in the patients with diabetes caused by an INS mutation will be crucial to define new treatments. As in the Akita mouse model, it may relate to the general concept of protein toxicity [30]. Strategies to increase insulin secretion by upregulating the normal allele of the INS gene may be applicable [3] and siRNA therapy for INS mutation is to be considered. Since INS mutations usually results in accumulation of a misfolded proinsulin molecule in the endoplasmic reticulum (ER), leading to ER stress and $\beta$-cell apoptosis [9], insulin is considered the only treatment currently available [31].

In summary, our case report highlighted the role of insulin gene mutation as a cause of neonatal diabetes in Saudi Arabia which was not noted as a common cause of neonatal diabetes before. To the best of our knowledge, this is the first reported case worldwide monozygotic twins presented with PNDM with INS gene mutation. The only reported monozygotic twins with PNDM are due to KCNJ11 mutation of the K-ATP channel [32].

We recommend that genetic testing for both the insulin gene as well as the channel mutations be carried out in all cases of neonatal diabetes and their parents, to identify the risk of recurrence in other siblings and meanwhile, this will help in premarital counseling in a community like Saudi Arabia with very high incidence of consanguineous marriage. It will also uncover cases which present late and misdiagnosed as type 1 DM in absence of positive autoantibodies.

\section{Acknowledgement}

"The molecular genetic testing was performed by Dr. Sarah Flanagan at the University of Exeter Medical School and funded by a Wellcome Trust Senio Investigator award to Professor Sian Ellard and Professor Andrew Hattersley".

\section{References}

1. lafusco D, Massa O, Pasquino B, Colombo C, lughetti L, et al. (2012) Minimal incidence of neonatal/infancy onset diabetes in Italy is 1:90,000 live births. Acta Diabetol 49: 405-408.

2. Habeb AM, Al-Magamsi MS, Eid IM, Ali MI, Hattersley AT, et al. (2012) Incidence, genetics, and clinical phenotype of permanent neonatal diabetes mellitus in northwest Saudi Arabia. Pediatr Diabetes 13: 499-505.

3. Polak M, Dechaume A, Cavé H, Nimri R, Crosnier H, et al. (2008) Heterozygous missense mutations in the insulin gene are linked to permanent diabetes appearing in the neonatal period or in early infancy: a report from the French ND (Neonatal Diabetes) Study Group. Diabetes 57: 1115-1119.

4. Aguilar-Bryan L, Bryan J (2008) Neonatal diabetes mellitus. Endocr Rev 29 265-291.

5. Murphy R, Ellard S, Hattersley AT (2008) Clinical implications of a molecular genetic classification of monogenic beta-cell diabetes. Nat Clin Pract Endocrinol Metab 4: 200-213

6. Gloyn AL, Pearson ER, Antcliff JF, Proks P, Bruining GJ, et al. (2004) Activating mutations in the gene encoding the ATP-sensitive potassium-channel subunit Kir6.2 and permanent neonatal diabetes. N Engl J Med 350: 1838-1849.

7. Babenko AP, Polak M, Cavé H, Busiah K, Czernichow P, et al. (2006) Activating mutations in the ABCC8 gene in neonatal diabetes mellitus. N Engl J Med 355: 456-466.

8. Støy J, Edghill EL, Flanagan SE, Ye H, Paz VP, et al. (2007) Insulin gene mutations as a cause of permanent neonatal diabetes. Proc Natl Acad Sci U S A 104: 15040-15044.

9. Colombo C, Porzio O, Liu M, Massa O, Vasta M, et al. (2008) Seven mutations in the human insulin gene linked to permanent neonatal/infancy-onset diabetes mellitus. J Clin Invest 118: 2148-2156.

10. Ellard S, Flanagan SE, Girard CA, Patch AM, Harries LW, et al. (2007) Permanent neonatal diabetes caused by dominant, recessive, or compound heterozygous SUR1 mutations with opposite functional effects. Am J Hum Genet 81: 375-382.

11. Stoffers DA, Zinkin NT, Stanojevic V, Clarke WL, Habener JF (1997) Pancreatic agenesis attributable to a single nucleotide deletion in the human IPF1 gene coding sequence. Nat Genet 15: 106-110.

12. Delépine M, Nicolino M, Barrett T, Golamaully M, Lathrop GM, et al. (2000) EIF2AK3, encoding translation initiation factor 2-alpha kinase 3, is mutated in patients with Wolcott-Rallison syndrome. Nat Genet 25: 406-409. 
Citation: Talaat IM, Kamal NM, Alghamdi H (2014) Permanent Neonatal DM in Monozygotic Twins with p.C109Y Mutation in INS Gene: First Report from Saudi Arabia. J Diabetes Metab 5: 332. doi:10.4172/2155-6156.1000332

Page 4 of 4

13. Sellick GS, Barker KT, Stolte-Dijkstra I, Fleischmann C, Coleman RJ, et al. (2004) Mutations in PTF1A cause pancreatic and cerebellar agenesis. Nat Genet 36: 1301-1305.

14. Senée V, Chelala C, Duchatelet S, Feng D, Blanc H, et al. (2006) Mutations in GLIS3 are responsible for a rare syndrome with neonatal diabetes mellitus and congenital hypothyroidism. Nat Genet 38: 682-687.

15. Smith SB, Qu HQ, Taleb N, Kishimoto NY, Scheel DW, et al. (2010) Rfx6 directs islet formation and insulin production in mice and humans. Nature 463: 775 780

16. Senée V, Vattem KM, Delépine M, Rainbow LA, Haton C, et al. (2004) WolcottRallison Syndrome: clinical, genetic, and functional study of EIF2AK3 mutations and suggestion of genetic heterogeneity. Diabetes 53: 1876-1883.

17. Bennett CL, Christie J, Ramsdell F, Brunkow ME, Ferguson PJ, et al. (2001) The immune dysregulation, polyendocrinopathy, enteropathy, $X$-linked syndrome (IPEX) is caused by mutations of FOXP3. Nat Genet 27: 20-21.

18. Njølstad PR, Søvik O, Cuesta-Muñoz A, Bjørkhaug L, Massa O, et al. (2001) Neonatal diabetes mellitus due to complete glucokinase deficiency. $\mathrm{N}$ Engl $\mathrm{J}$ Med 344: 1588-1592.

19. Støy J, Greeley SA, Paz VP, Ye H, Pastore AN, et al. (2008) Diagnosis and treatment of neonatal diabetes: a United States experience. Pediatr Diabetes 9: 450-459.

20. Edghill EL, Flanagan SE, Patch AM, Boustred C, Parrish A, et al. (2008) Insulin mutation screening in 1,044 patients with diabetes: mutations in the INS gene are a common cause of neonatal diabetes but a rare cause of diabetes diagnosed in childhood or adulthood. Diabetes 57: 1034-1042.

21. Raile K, O'Connell M, Galler A, Werther G, Kühnen P, et al. (2011) Diabetes caused by insulin gene (INS) deletion: clinical characteristics of homozygous and heterozygous individuals. Eur J Endocrinol 165: 255-260.

22. Kamal Alanani NM, Alsulaimani AA (2013) Epidemiological pattern of newly diagnosed children with type 1 diabetes mellitus, Taif, Saudi Arabia. ScientificWorldJournal 2013: 421569.
23. Ahamed A, Unnikrishnan AG, Pendsey SS, Nampoothiri S, Bhavani N, et al. (2008) Permanent neonatal diabetes mellitus due to a C96Y heterozygous mutation in the insulin gene. A case report. JOP 9: 715-718.

24. Catli G, Abaci A, Flanagan SE, Anik A, Ellard S, et al. (2013) Permanent neonatal diabetes caused by a novel mutation in the INS gene. Diabetes Res Clin Pract 99: e5-8.

25. Bee YM, Zhao Y, Ellard S, Hattersley AT, Yap F (2013) Permanent neonata diabetes in siblings with novel C109Y INS mutation transmitted by an unaffected parent with somatic mosaicism. Pediatr Diabetes .

26. Edghill EL, Gloyn AL, Goriely A, Harries LW, Flanagan SE, et al. (2007) Origin of de novo KCNJ11 mutations and risk of neonatal diabetes for subsequent siblings. J Clin Endocrinol Metab 92: 1773-1777.

27. Wang J, Takeuchi T, Tanaka S, Kubo SK, Kayo T, et al. (1999) A mutation in the insulin 2 gene induces diabetes with severe pancreatic beta-cell dysfunction in the Mody mouse. J Clin Invest 103: 27-37.

28. Molven A, Ringdal M, Nordbø AM, Raeder H, Støy J, et al. (2008) Mutations in the insulin gene can cause MODY and autoantibody-negative type 1 diabetes. Diabetes 57: 1131-1135.

29. Rubio-Cabezas O, Edghill EL, Argente J, Hattersley AT (2009) Testing fo monogenic diabetes among children and adolescents with antibody-negative clinically defined Type 1 diabetes. Diabet Med 26: 1070-1074

30. Ron D (2002) Proteotoxicity in the endoplasmic reticulum: lessons from the Akita diabetic mouse. J Clin Invest 109: 443-445.

31. Rubio-Cabezas O, Ellard S (2013) Diabetes mellitus in neonates and infants: genetic heterogeneity, clinical approach to diagnosis, and therapeutic options. Horm Res Paediatr 80: 137-146.

32. Hicks KA, Kushner JA, Heptulla R, Ham JN (2014) Permanent neonata diabetes mellitus in monozygotic twins achieving low-dose sulfonylurea therapy. J Pediatr Endocrinol Metab 27: 135-138.
This article was originally published in a special issue, Diabetes: Case Studies handled by Editors. Dr. Vishwamitra Sharma, Nottingham University Hospital, United Kingdom 